\title{
ARTICLE Propofol affects mouse embryonic fibroblast survival and proliferation in vitro via ATG5- and calcium-dependent regulation of autophagy
}

\author{
Zhen-dong $\mathrm{Xu}^{1,2}$, Yong Wang ${ }^{1,3}$, Ge Liang ${ }^{1}$, Zhi-qiang $\mathrm{Liu}^{2}$, Wu-hua Ma ${ }^{3}$, Charleen T Chu ${ }^{4}$ and Hua-feng Wei ${ }^{1}$
}

Propofol is a commonly used intravenous anesthetic agent, which has been found to affect cell survival and proliferation especially in early life. Our previous studies show that propofol-induced neurodegeneration and neurogenesis are closely associated with cell autophagy. In the present study we explored the roles of autophagy-related gene 5 (ATG5) in propofol-induced autophagy in mouse embryonic fibroblasts (MEF) in vitro. We showed that ATG5 was functionally related to propofol-induced cell survival and damage: propofol significantly enhanced cell survival and proliferation at a clinically relevant dose (10 $\mu \mathrm{M})$, but caused cell death at an extremely high concentration $(200 \mu \mathrm{M})$ in ATG5 $5^{-1-} \mathrm{MEF}$, but not in WT cells. The dual effects found in ATG5 $5^{-1-}$ MEF could be blocked by intracellular $\mathrm{Ca}^{2+}$ channel antagonists. We also found that propofol evoked a moderate (promote cell growth) and extremely high (cause apoptosis) cytosolic $\mathrm{Ca}^{2+}$ elevation at the concentrations of $10 \mu \mathrm{M}$ and $200 \mu \mathrm{M}$, respectively, only in ATG5 ${ }^{-1-}$ MEF. In addition, $\mathrm{ATG}^{-1-}$ MEF themselves released more $\mathrm{Ca}^{2+}$ in cytosolic space and endoplasmic reticulum compared with WT cells, suggesting that autophagy deficiency made intracellular calcium signaling more vulnerable to external stimuli (propofol). Altogether, our results reveal that ATG5 plays a crucial role in propofol regulation of cell survival and proliferation by affecting intracellular $\mathrm{Ca}^{2+}$ homeostasis.

Keywords: propofol; autophagy; ATG5; calcium; InsP 3 receptors; ryanodine receptors; mouse embryonic fibroblasts

Acta Pharmacologica Sinica (2020) 41:303-310; https://doi.org/10.1038/s41401-019-0303-z

\section{INTRODUCTION}

Autophagy-related gene 5 (ATG5) is one of the key proteins regulating autophagy activity [1-3], which is also associated with intracellular $\mathrm{Ca}^{2+}$ homeostasis [4-6]. ATG5 has been demonstrated to affect cell survival and proliferation via its effects on autophagy [7-9]. Similar to other important autophagy regulators, such as mTOR and Beclin-1, ATG5 can be targeted to change autophagy activity and therefore affect the pathology of some diseases, such as Parkinson's disease [10], myeloid leukemia [11], and some tumors $[12,13]$. ATG5 knockout cells are generated $[1,14]$ and available so that the effects of drugs on cell physiology/pathology via the function of ATG5 and associated autophagy activity can be investigated conveniently.

Our previous studies suggested that propofol can regulate cell autophagy via activation of $\operatorname{Ins}_{3}\left(\operatorname{Ins}_{3} \mathrm{R}\right)$ or ryanodine receptors (RYR) $[15,16]$, with unclear mechanisms. Calcium may also be involved in autophagy by affecting ATG5. Elevation of intracellular $\mathrm{Ca}^{2+}$ levels can activate Atg5, which initiates autophagy [4]. Interestingly, reducing intracellular $\mathrm{Ca}^{2+}$ prevents the cleavage of ATG5, which in turn increases the levels of full-length ATG5 and ATG12-ATG5 conjugate [17]. Considering the essential role of
ATG5 in autophagy and calcium regulation [18], it is plausible that propofol may affect cell survival or proliferation by varying the function of ATG5. Although propofol at high concentrations has been demonstrated to cause neurotoxicity and impairment of neurogenesis [19-21], the effects of propofol at clinically relevant low concentrations on autophagy and cell function need to be investigated. Here, we studied the effects of propofol on cell survival, growth and autophagy activity in both wild-type (WT) and ATG5 knockout cells (ATG5 ${ }^{-1-}$ ). We demonstrated that ATG5 plays an important role in propofol effects on autophagy, cell survival, and growth due to its effects on the regulation of intracellular $\mathrm{Ca}^{2+}$ homeostasis.

\section{MATERIALS AND METHODS}

Cell culture

WT and $\mathrm{ATG}^{-1-}$ mouse embryonic fibroblast (MEF) cell lines purchased from RIKEN Bio Resource Center (Tsukuba, Ibaraki 305-0074, Japan) were maintained in Dulbecco's Modified Eagle's Medium, supplemented with $10 \%$ fetal bovine serum and $1 \%$ penicillin/streptomycin (Both from Life Technologies, Carlsbad, CA,

\footnotetext{
${ }^{1}$ Department of Anesthesiology and Critical Care, Perelman School of Medicine, University of Pennsylvania, Philadelphia, PA 19104, USA; ${ }^{2}$ Department of Anesthesiology, Shanghai First Maternity and Infant Hospital, Tongji University School of Medicine, Shanghai 201204, China; ${ }^{3}$ Department of Anesthesiology, The First Affiliated Hospital of

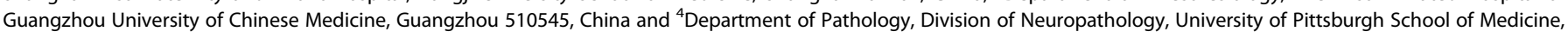
Pittsburgh, PA 15261, USA

Correspondence: Hua-feng Wei (weih@uphs.upenn.edu)

These authors contributed equally: Zhen-dong $\mathrm{Xu}$, Yong Wang
}

Received: 12 April 2019 Accepted: 29 August 2019

Published online: 23 October 2019 
USA) and were cultured in a $5 \% \mathrm{CO}_{2}$ humidified atmosphere at $37^{\circ} \mathrm{C}$. The culture medium was changed every two days. Cells with $80 \%-85 \%$ confluence were obtained from T-flask cultures using trypsinization and incubated onto the disk samples.

\section{Cell viability}

The cell viability/proliferation was determined using the MTT (3-(4,5dimethylthiazol-2-yl)-2,5-diphenyltetrazolium bromide, Sigma-Aldrich, St. Louis, MO, USA) assay at 6,12 , and $24 \mathrm{~h}$ as previously described [15]. After washing with PBS, the cells were incubated with fresh culture medium containing MTT $(0.5 \mathrm{mg} / \mathrm{mL}$ in the medium) at 37 ${ }^{\circ} \mathrm{C}$ for $4 \mathrm{~h}$ in the dark. The medium was then removed, and formazan was solubilized with dimethyl sulfoxide. The absorbance of this solution in each well was quantified by spectrophotometry at $540 \mathrm{~nm}$ using a Synergy ${ }^{\mathrm{TM}} \mathrm{H} 1$ microplate reader (BioTek, Winooski, VT, USA).

Cell viability was further confirmed by the trypan blue assay. Then, $1 \times 10^{4}$ cells per well were seeded onto 24 -well plates. Following propofol treatment, cell viability was determined by trypan blue exclusion assay. Cells were mixed with $0.4 \%$ trypan blue solution for $5 \mathrm{~min}$ at room temperature. The cell number was countered with a hemocytometer in a bright field under a microscope as described previously [22]. Cells without trypan blue entry were regarded as viable.

Cytotoxicity was determined by lactate-dehydrogenase (LDH) detection with an LDH-release assay kit (Thermo Scientific, Rockford, IL, USA) according to the manufacturer's instructions, as described previously [15]. Briefly, $50 \mu \mathrm{L}$ of supernatant was collected and transferred to each well of a new 96-well plate. Then, $50 \mu \mathrm{L}$ of reaction mixture was added to each well. After $30 \mathrm{~min}$ of incubation at room temperature, $50 \mu \mathrm{L}$ of stop solution was added to terminate the reaction. The $490 \mathrm{~nm}$ absorbance of the samples was measured along with background absorbance at $680 \mathrm{~nm}$ using a Synergy ${ }^{\mathrm{TM}} \mathrm{H} 1$ microplate reader (BioTek, Winooski, VT, USA).

Cell proliferation assays

WT and ATG5 ${ }^{-1-}$ MEFs were plated onto cover glasses in culture medium. 5-Bromodeoxyuridine (BrdU, Invitrogen, Eugene, OR, USA) was added to the culture medium for $4 \mathrm{~h}$ before the end of treatment with a final concentration of $10 \mu \mathrm{M}$. The cells were then fixed in $4 \%$ paraformaldehyde and permeabilized with $0.1 \%$ Triton $\mathrm{X}-100$. For BrdU detection, acid treatment $(1 \mathrm{~N} \mathrm{HCL} 10$ min on ice followed by $2 \mathrm{~N} \mathrm{HCL} 10 \mathrm{~min}$ at room temperature) separated DNA into single strands so that the primary antibody could access the incorporated BrdU. After incubation with blocking solution (5\% normal goat serum in PBS containing $0.1 \%$ Triton X-100), the cells were incubated with rat monoclonal anti-BrdU primary antibody (1:100; Santa Cruz Biotechnology, Dallas, TX, USA) overnight at $4{ }^{\circ} \mathrm{C}$. After a subsequent wash with PBS containing $0.1 \%$ Triton X-100, the cells were incubated with fluorescently labeled secondary antibody conjugated with anti-rat lgG (1:1000; Invitrogen, Eugene, OR) for $2 \mathrm{~h}$ at room temperature. Cell nuclei were counterstained with $4^{\prime}, 6-$ diamidino-2-phenylindole (DAPI, Invitrogen, Eugene, OR, USA) for 5 min at room temperature. The immunostained cells were covered and then mounted on an Olympus BX41TF fluorescence microscope (200x; Olympus USA, Center Valley, PA, USA). Images were acquired using iVision 10.10.5 software (Biovision Technologies, Exton, PA, USA). Five sets of images were acquired at random locations on the cover glass and were subsequently merged using ImageJ $1.49 \mathrm{v}$ software (National Institutes of Health, Bethesda, MD, USA). The percentage of BrdU-positive cells over the total number of cells was calculated and compared across different groups from at least three different cultures.

\section{$\mathrm{Ca}^{2+}$ measurements}

The level of cytosolic $\mathrm{Ca}^{2+}$ concentration $\left(\left[\mathrm{Ca}^{2+}\right]_{\mathrm{c}}\right)$ of MEFs with or without propofol treatment was measured by Fura-2/AM fluorescence (Molecular probe, Eugene, OR, USA) using a previously described method $[15,16]$. The assays were carried out on an Olympus IX70 inverted microscope (Olympus America Inc., Center Valley, PA, USA) and IPLab v3.71 software (Scanalytics, Milwaukee WI, USA). Briefly, MEFs were plated onto a 35$\mathrm{mm}$ culture dish. After the cells were washed three times in Hank's buffered salt solution (HBSS) containing $\mathrm{Mg}^{2+}$ and $\mathrm{Ca}^{2+}$ and loaded with $2.5 \mu \mathrm{M}$ Fura-2/AM in the same buffer for $30 \mathrm{~min}$ at $37^{\circ} \mathrm{C}$, the cells were then washed twice and incubated with HBSS for another $30 \mathrm{~min}$ at $37^{\circ} \mathrm{C}$. Fura-2AM was measured by recording alternate at 340 and $380 \mathrm{~nm}$ excitation, and emission at $510 \mathrm{~nm}$ was detected for up to $10 \mathrm{~min}$ for each treatment. The evoked changes were recorded in response to treatment with $10 \mu \mathrm{M}$ versus $200 \mu \mathrm{M}$ propofol with or without dantrolene (Dan), Xestospongin $\mathrm{C}(\mathrm{Xc})$ or BAPTA-AM. The results are presented as a ratio of F340/F380 nm and averaged from at least three separate experiments.

Basal calcium in the cytoplasm and ER in ATG5 $5^{-1-}$ and WT MEFs MEF cells were plated on $15-\mathrm{mm}$ round coverslips in 24-well plates and then cultured overnight. The next day, plasmid pCMVRCEPIA1er (58216; Addgene, Cambridge, MA, USA) was transfected with Lipofectamine 3000 (L3000008; Invitrogen, Carlsbad, CA, USA) according to the manufacturer's instructions. At $24 \mathrm{~h}$ post transfection, the transfection reagent was replaced by the normal culture medium and the treatment was applied. Images were taken at the end of the treatment. For labeling intracellular $\mathrm{Ca}^{2+}$, cells were incubated with Fluo-4 AM reagent (F14201; Molecular Probes, Eugene, OR, USA) at $3 \mu \mathrm{M}$ for $40 \mathrm{~min}$ at $37^{\circ} \mathrm{C}$.

\section{Immunoblotting}

Western blotting was performed according to the standard procedure and as we described before [15]. Total protein extracts from MEFs cells were obtained by lysing the cells in ice-cold lysis buffer $(50 \mathrm{mM}$ Tris- $\mathrm{HCl}, 150 \mathrm{mM} \mathrm{NaCl}$ and $1 \%$ Triton X-100) in the presence of a cocktail of protease inhibitors [23]. After centrifugation, the supernatant was collected, and the total protein was quantified using a bicinchoninic acid protein assay kit (Thermo Scientific, Rockford, IL, USA). Equal amounts of protein for each lane were loaded and separated on $15 \%$ sodium dodecyl sulfatepolyacrylamide gel electrophoresis (SDS-PAGE). After electrophoresis, the proteins were transferred onto a polyvinylidene fluoride (PVDF) membrane. The membranes were blocked with $5 \%$ fat-free milk dissolved in PBS-T for $1 \mathrm{~h}$ at room temperature and then stained with primary antibody at $4{ }^{\circ} \mathrm{C}$ overnight. After washing with PBS-T, the membranes were incubated with secondary antibodies (HRP conjugated anti-rabbit and anti-mouse $\operatorname{lgG}$ ) at $1: 1000$ dilutions, and $\beta$-actin served as a loading control. Signals were detected with an enhanced chemiluminescence detection system (Millipore, Billerica, MA, USA) and quantified by scanning densitometry.

Data analysis and statistics

Parametric variables were expressed as the mean $\pm S D$ and analyzed using the Student's unpaired two-tailed $t$ test, one-way or two-way ANOVA, followed by Tukey's post hoc analysis. GraphPad Prism software (GraphPad Software, Inc., San Diego, (A, USA) was used for statistical analyses and graph creation. $P$ values less than 0.05 were considered statistically significant.

\section{RESULTS}

Propofol affects cell survival in an ATG5-dependent manner and is associated with intracellular $\mathrm{Ca}^{2+}$ channels

We first determined whether propofol affects cell viability in $\mathrm{ATG5}^{-/-}$and WT cells by MTT and LDH detection. After 24-h exposure to propofol, the MTT signal of $\mathrm{ATG} 5^{-1-}$ cells was significantly enhanced at clinically relevant concentrations $(10 \mu \mathrm{M})$; however, this effect was inverted at high pharmacological 

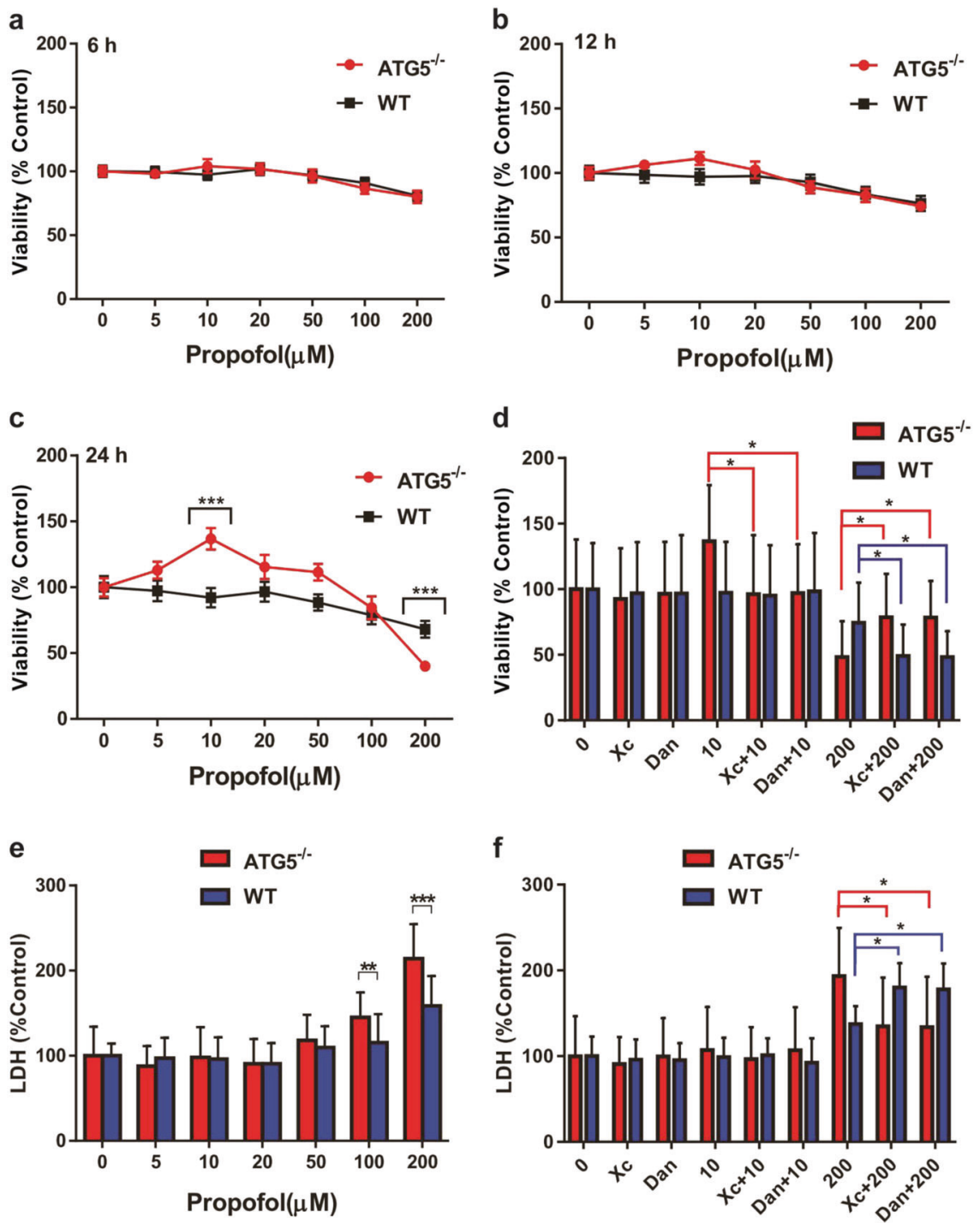

Fig. 1 Propofol dose- and time-dependently affected cell viability and cytotoxicity via activation of InsP $\mathrm{P}_{3}$ (InsP $\left.\mathrm{P}_{3} \mathrm{R}\right)$ or ryanodine (RYR) receptors in an ATG5-dependent manner. Cell viability was measured by 3-(4,5-dimethylthiazol-2-yl)-2,5-diphenyl-tetrazolium bromide (MTT), and cytotoxicity was determined by lactate-dehydrogenase (LDH) reduction assay in wild type (WT) and ATG5 ${ }^{-1-}$ mouse embryonic fibroblast cells (MEFs). WT and ATG5 ${ }^{-1-}$ MEFs were exposed to different propofol concentrations for $6(\mathbf{a}, n=15), 12(\mathbf{b}, n=15)$, and $24 \mathrm{~h}(\mathbf{c}, n=16)$. Treatment with $10 \mu \mathrm{M}$ propofol for $24-\mathrm{h}$ increased, while $200 \mu \mathrm{M}$ propofol decreased the viability of ATG5 $5^{-1-}$ cells but not WT MEFs at corresponding time points (c). d WT MEFs were exposed to 10 and $200 \mu \mathrm{M}$ propofol treatment for $24 \mathrm{~h}$ with or without cotreatment with antagonists for Ins $P_{3} R$ (xestospongin C or Xc $100 \mathrm{nM}$ ) or RYR (dantrolene or Dan $20 \mu \mathrm{M}$ ). Xc or Dan significantly inhibited the effects of 10 and $200 \mu \mathrm{M}$ propofol in ATG5 $5^{-1-}$ MEFs, and of $200 \mu \mathrm{M}$ propofol in WT MEFs. e Treatment with 100 and $200 \mu \mathrm{M}$ propofol for $24 \mathrm{~h}$ significantly

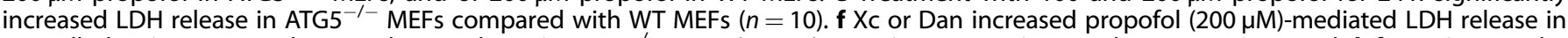
WT cells, but in contrast, decreased LDH release in ATG5 $5^{-1-}$ MEFs $(n=12)$. Data in a-c are given as the mean \pm SEM, and $\mathbf{d}-\mathbf{f}$ are given as the mean \pm SD. All data are from at least three separate experiments and analyzed by two-way ANOVA followed by the Tukey's multiple comparison tests. ${ }^{*} P<0.05,{ }^{* *} P<0.01$, or ${ }^{* * *} P<0.001$, respectively

concentrations (200 $\mu \mathrm{M}$, Fig. 1c). Toxic effects of ATG5 deficiency at high doses were further confirmed by LDH detection (Fig. 1e). In contrast, propofol did not significantly affect cell survival at any tested concentration in WT cells. According to our prior study $[15,16]$, we hypothesized that intracellular calcium channels, such as inositol-1,4,5-trisphosphate receptor $\left(\operatorname{lns}_{3} \mathrm{R}\right)$ and RYR located in the sarcoplasmic/endoplasmic reticulum membrane, may be involved in propofol-induced cell survival. Indeed, the ability of $10 \mu \mathrm{M}$ propofol to increase viability in ATG $5^{-1-}$ cells was blocked by the antagonists of InsP $\mathrm{P}_{3} \mathrm{R}$ and RYR (Fig. 1d), which also blocked the toxic effects at the high $200 \mu \mathrm{M}$ dose (Fig. 1d, f). In contrast, treatment with $200 \mu \mathrm{M}$ propofol became harmful to WT cells after the inhibition of Ins $\mathrm{P}_{3} \mathrm{R}$ and RYR (Fig. 1d, f). These results indicate that autophagy deficiency may facilitate intracellular $\mathrm{Ca}^{2+}$ channel opening, which triggers the dual functional effects of propofol on survival in $\mathrm{ATG} 5^{-1-}$ cells.

ATG5 plays a key role in propofol effects on cell growth We next determined whether the elevation of MTT by propofol at clinically relevant concentrations in $\mathrm{ATG} 5^{-1-}$ cells (Fig. 1c) was caused by changes in mitochondrial reductase activity (early cell damage) or an increase in cell numbers (proliferation). Propofol at a low concentration $(10 \mu \mathrm{M})$ significantly increased both total viable cells (Fig. 2c) as determined by the trypan blue assay and newly derived cells (Fig. 2a, b) as determined by the BrdU incorporation assay. In contrast, propofol at a high concentration 
a
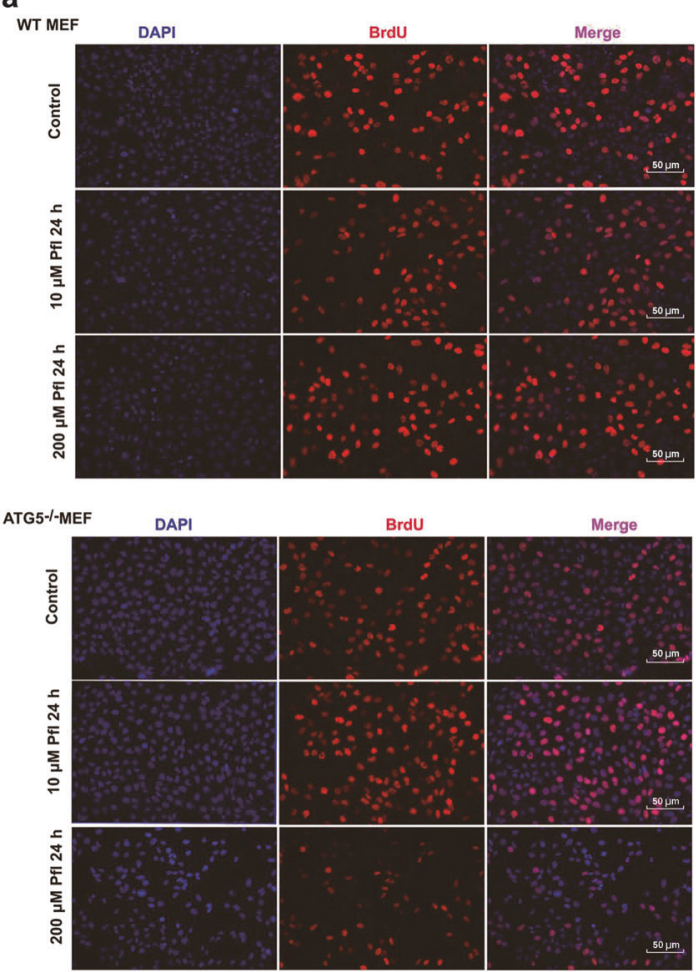

b

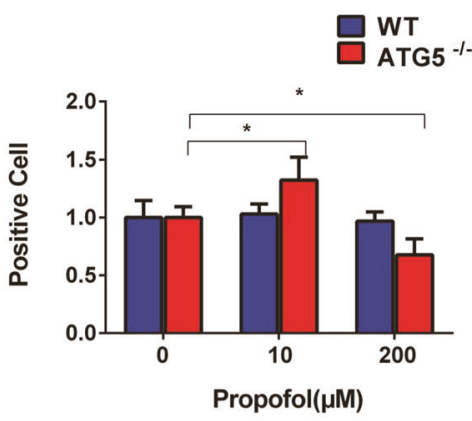

C

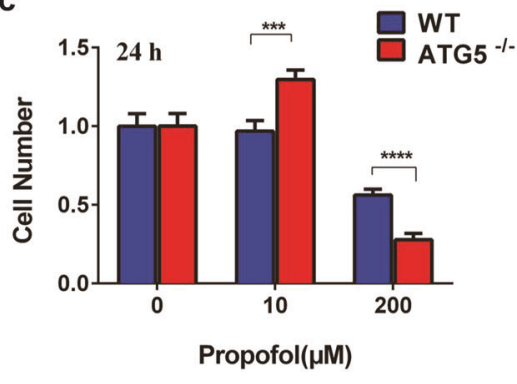

Fig. 2 Propofol affected cell proliferation via an ATG5-dependent pathway. a Representative images showing the double immunostaining of DAPI (blue, arrows) and 5-bromodeoxyuridine (BrdU, red) in WT or ATG5 knockout (ATG5 $5^{-1}$ ) mouse embryonic fibroblast cells (MEFs) after treatment with propofol at 10 or $200 \mu \mathrm{M}$. Scale bar $=50 \mu \mathrm{m}$; Cell proliferation was determined by BrdU incorporation (a, b) or viable cell number count by trypan blue exclusion assay c. The percentage of BrdU-positive cells (b) or the number of viable cells (c) treated with propofol for $24-\mathrm{h}$ increased at clinically relevant concentrations $(10 \mu \mathrm{M})$ but decreased at pharmacologically high concentrations $(200 \mu \mathrm{M})$, most significantly in ATG5 ${ }^{-1-}$ cells compared with WT cells $(n=30)$. All data are presented as the mean \pm SD from three separate experiments and analyzed by one-way ANOVA followed by the Tukey's multiple comparison tests. ${ }^{*} P<0.05$, ${ }^{* *} P<0.001$, or ${ }^{* * * *} P<0.0001$, respectively

$(200 \mu \mathrm{M})$ decreased the total cell numbers more significantly in $\mathrm{ATG}^{-1-}$ cells than in WT cells (Fig. $2 \mathrm{a}-\mathrm{C}$ ).

ATG5 is necessary for propofol-induced functional effects on autophagy activity

ATG5 plays an essential role in the induction and regulation of autophagy activity, but it is still unclear how propofol mediates functional effects by autophagy. We first confirmed that propofol up to $200 \mu \mathrm{M}$ did not affect ATG5 expression and that no ATG5 existed in $\mathrm{ATG}^{-1-}$ cells using Western blotting (Fig. 3a). In addition, propofol did not produce a significant change in ATG5 in WT cells (Fig. 3c). Since autophagy flux, which is a dynamic process, consists of several sequential steps-sequestration, transport to lysosomes, degradation, and utilization of degradation products, it is possible that autophagy activity is altered despite unchanged ATG5 protein expression. To further study this possibility, we applied bafilomycin $A_{1}\left(\right.$ Baf $\left.A_{1}\right)$, which can prevent fusion of the autophagosome and lysosomes. We found that 200 $\mu \mathrm{M}$ but not $10 \mu \mathrm{M}$ propofol significantly increased the expression of LC3 II, a biomarker to detect autophagy, by pretreatment with Baf $A_{1}$ in WT cells (Fig. 3b, d), indicating that high concentrations of propofol can induce autophagy. As expected, there was no LC3 II protein bands formed in ATG $5^{-1-}$ cells (Fig. 3b). These findings suggest that the enhanced cell death in $\mathrm{Atg}^{-1-}$ cells treated with $200 \mu \mathrm{M}$ could be related to inability to activate autophagy.

Propofol facilitates cytosolic $\mathrm{Ca}^{2+}$ release in ATG5-deficient cells Our previous studies have shown that propofol increases intracellular $\mathrm{Ca}^{2+}$ release in different types of cells $[15,16]$. To further confirm the change in basal $\mathrm{Ca}^{2+}$ release in both the cytoplasm and ER, we measured these effects by Fluo-4 AM dye on an inverted microscope and $\mathrm{ER} \mathrm{Ca}^{2+}$ transfected with CEPIA1er (Fig. 4a). We found that basal cytosolic and $\mathrm{ER} \mathrm{Ca}{ }^{2+}$ were significantly increased in ATG5 ${ }^{-1-}$ cells compared with WT cells (Fig. 4b). In addition, propofol-mediated $\mathrm{Ca}^{2+}$ release could be inhibited by Xc or dantrolene (Fig. 5e, f, Xc, $100 \mathrm{nM}$, dantrolene 20 $\mu \mathrm{M})$, confirming the involvement of intracellular calcium channels.

It is possible that the dual functional effects of propofol on ATG5 ${ }^{-1-}$ cells (Fig. 1) may be due to various degrees of intracellular $\mathrm{Ca}^{2+}$ release at different concentrations. Figure 5 shows that propofol at extremely high concentrations $(200 \mu \mathrm{M})$ increased $\left[\mathrm{Ca}^{2+}\right]_{c}$ more robustly than at clinically relevant concentrations $(10 \mu \mathrm{M})$ in $\mathrm{ATG} 5^{-1-}$ cells, compared with WT cells. These results suggest that autophagy-deficient cells are primed for greater lability in response to $\mathrm{Ca}^{2+}$ mobilizing stimuli. Moderate intracellular $\mathrm{Ca}^{2+}$ release enhances cell survival/ proliferation, but over release causes cell death, which could be supported by the results shown in Fig. 1.

\section{DISCUSSION}

We have demonstrated that ATG5 is essential for propofol effects on cell survival and growth. The above effects may be related to propofol effects on Ins $\mathrm{P}_{3} \mathrm{R} / \mathrm{RYR}$ activity and changes in intracellular $\mathrm{Ca}^{2+}$ homeostasis. This study provides a detailed mechanism of propofol regulation of autophagy and associated cell survival or growth.

Although commonly used inhalational anesthetics (sevoflurane, isoflurane, or desflurane) $[24,25]$ and intravenous anesthetics (propofol) [15] all have been shown to cause $\mathrm{Ca}^{2+}$ release from the ER, their potency to affect intracellular $\mathrm{Ca}^{2+}$ homeostasis is quite different. Inhalational anesthetics at clinically relevant 
a
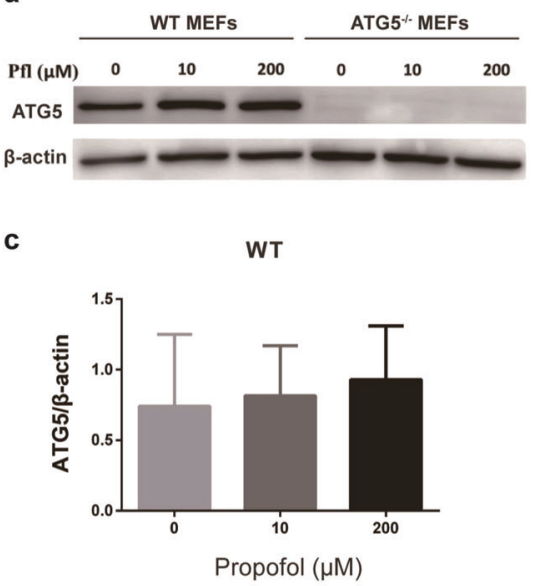

b

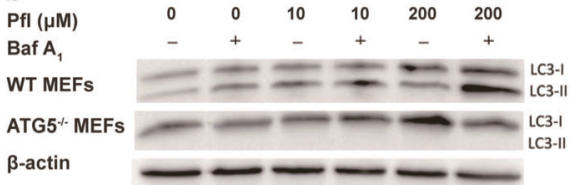

d

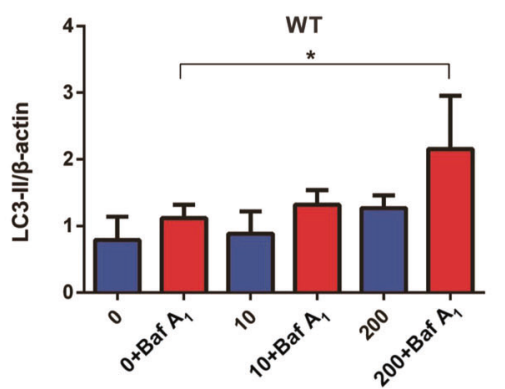

Fig. 3 ATG5 is essential for propofol effects on autophagy. Knockout of ATG5 (ATG5 ${ }^{-/}$) protein was confirmed using Western blotting compared with WT MEFs (a). Propofol at clinically relevant $(10 \mu \mathrm{M})$ or pharmacological $(200 \mu \mathrm{M})$ concentrations did not affect ATG5 protein levels (c). Propofol only affected the autophagy biomarker LC3-II in WT cells but not in ATG5 ${ }^{-/-}$cells because there were no LC3 II signals at any condition in ATG5 ${ }^{-1-}$ cells (b). The addition of $200 \mu \mathrm{M}$ propofol in the presence of bafilomycin (100 nM) significantly elevated LC 3 II, suggesting that propofol promotes autophagy induction in WT MEFs (b, d). All data are given as the mean \pm SD from four separate experiments and analyzed by one-way ANOVA followed by the Dunnett's multiple comparisons test. ${ }^{*} P<0.05$

a

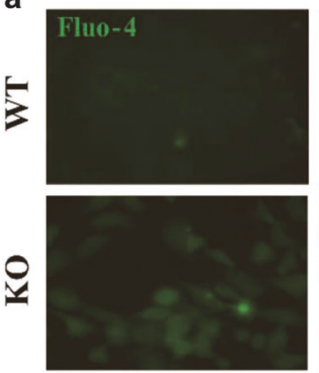

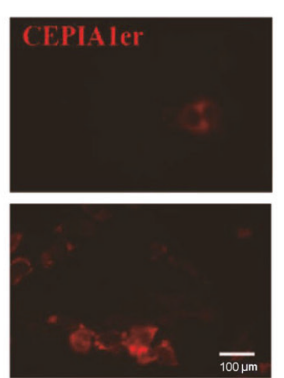

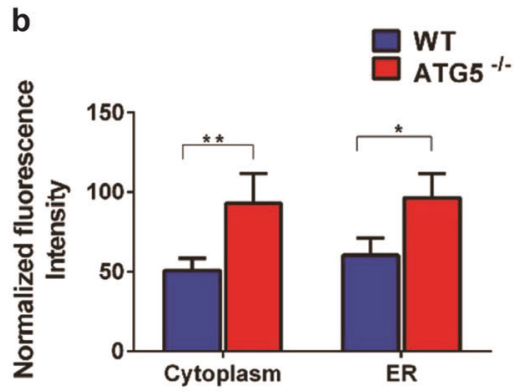

Fig. 4 Basal level $\mathrm{Ca}^{2+}$ concentriation in both cytosolic and ER significantly increased in ATG5 ${ }^{-1-}$ compared with wild type cells. The cytoplasmic $\mathrm{Ca}^{2+}$ concentration was measured using Fluo-4 AM dye on an inverted microscope and ER Ca ${ }^{2+}$ was measured in cells transfected with CEPIA 1 er (a). The $\mathrm{Ca}^{2+}$ concentrations in both the cytoplasm and ER were significantly increased in ATG5 ${ }^{-/-}$MEFs compared with WT MEFs (b). All data are presented as the mean \pm SD from three separate experiments and analyzed by the $t$ test. ${ }^{*} P<0.05,{ }^{* *} P<0.01$. All data are given as the mean \pm SD from three separate experiments and analyzed by the $t$ test. ${ }^{*} P<0.05,{ }^{* *} P<0.01$

concentrations (1-2 minimal alveolar concentration, MAC) can induce $\mathrm{Ca}^{2+}$ release from the $\mathrm{ER}$ via activation of $\operatorname{InsP}_{3} \mathrm{R}[24,26]$, with maximum activation at 1 MAC [26]. Inhalational anesthetics at clinically relevant concentrations can also induce cell damage in different types of cells $[25,27,28]$. However, propofol at clinically relevant concentrations $(1-20 \mu \mathrm{M})$ rarely induces elevation of $\left[\mathrm{Ca}^{2+}\right]_{c}$ or induced cell damage, and very high pharmacological concentrations $(>50 \mu \mathrm{M})$ are usually needed for propofol to induce the elevation of $\left[\mathrm{Ca}^{2+}\right]_{c}$ and cell damage [15]. Similar to previous research, the results of this study suggest that a high concentration of propofol $(>100 \mu \mathrm{M})$ is needed to cause cell death in ATG5 ${ }^{-1-}$ cells or cells with dysfunctional autophagy. In addition, propofol at a clinically relevant concentration $(10 \mu \mathrm{M})$ increased cell proliferation only in ATG5 $5^{-1-}$ but not WT cells, suggesting that the moderately enhanced $\mathrm{Ca}^{2+}$ release in autophagy-deficient cells crosses a threshold necessary to trigger proliferation. In combination with previous studies $[29,30]$, the results from this study suggest that propofol at clinically relevant concentrations $(<20 \mu \mathrm{M})$ typically does not cause cell damage in the presence of normal autophagy function. However, on the basis of impaired autophagy function, such as in Alzheimer's disease [31, 32], cells are more vulnerable to propofol-mediated cell cycle re-entry at low clinically relevant concentrations $(10 \mu \mathrm{M})$ and cell damage at high pharmacological concentrations $(>100 \mu \mathrm{M})$. Overall, these results suggest that propofol regulates cell survival and growth signaling by activating Ins $\mathrm{P}_{3} \mathrm{R} / \mathrm{RYR}$, but autophagy deficiency predisposes to calcium overload at high doses of propofol.

Previous studies have suggested that anesthetics elevated $\left[\mathrm{Ca}^{2+}\right]_{c}$ by the activation of InsP $P_{3} R / R Y R[15,16,24]$, but the effects of the autophagy regulatory factor ATG5 on the propofol-mediated $\mathrm{Ca}^{2+}$ response are not clear. In this study, we demonstrated that propofol induced a significantly higher $\left[\mathrm{Ca}^{2+}\right]_{c}$ in $\mathrm{ATG} 5^{--}$cells than in WT cells, and this effect can be inhibited by antagonists for $\operatorname{Ins} \mathrm{P}_{3} \mathrm{R}$ (Xc) or RYR (dantrolene). Interestingly, propofol, even at clinically relevant concentrations $(10 \mu \mathrm{M})$, increased $\left[\mathrm{Ca}^{2+}\right]_{\mathrm{c}}$, especially in $\mathrm{ATG}^{-/-}$cells. These results suggested that ATG5 might typically buffer the activation of InsP ${ }_{3} R / R Y R$ and affect intracellular $\mathrm{Ca}^{2+}$ homeostasis either directly or indirectly via its effects on autophagy activity [33].

Autophagy generally regulates the intracellular homeostasis of organelles such as the ER by sequestrating organelles and membrane compartments. Damaged or redundant ER can be removed by autophagy. ER is expanded when the autophagy pathway is impaired, and the $\mathrm{Ca}^{2+}$ stores in ER are also increased, consistent with the expansion of ER contents in autophagy-deficient cells $[18,33,34]$, which is in accordance with our results in the current study. However, it is not clear why cytosolic $\mathrm{Ca}^{2+}$ is also significantly increased in autophagy-deficient cells. Nevertheless, 
a

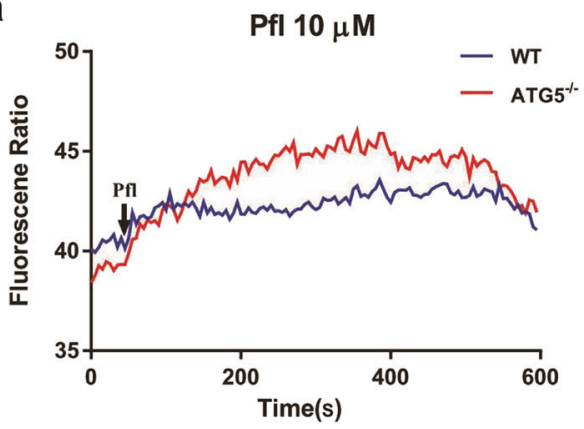

C

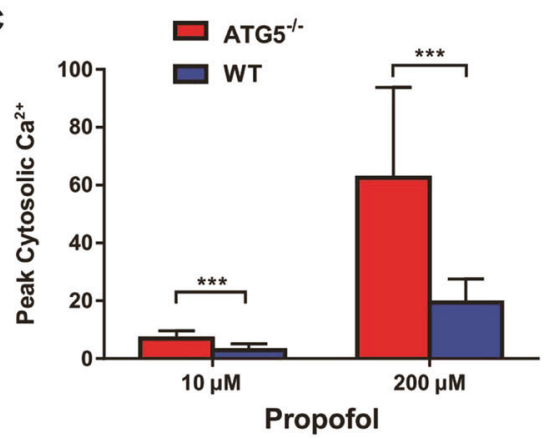

e

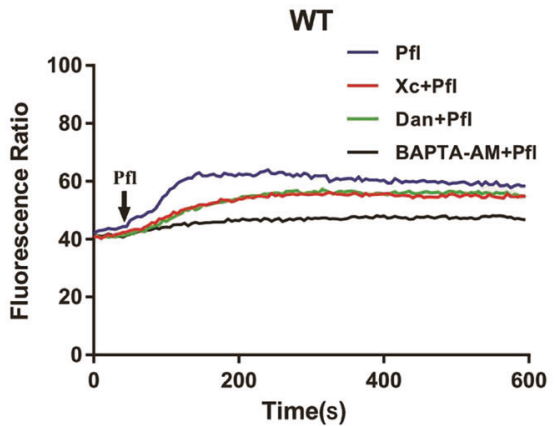

9

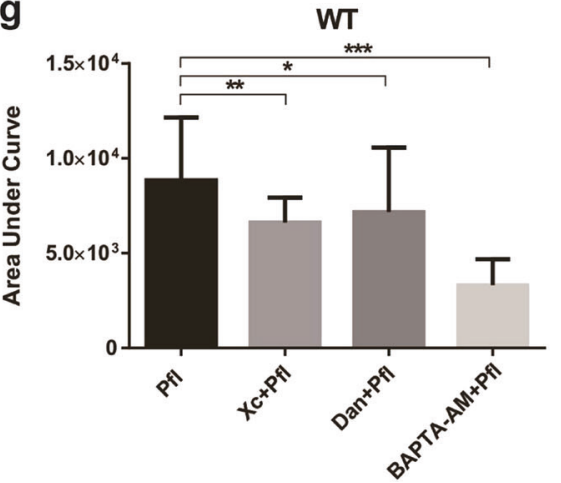

b

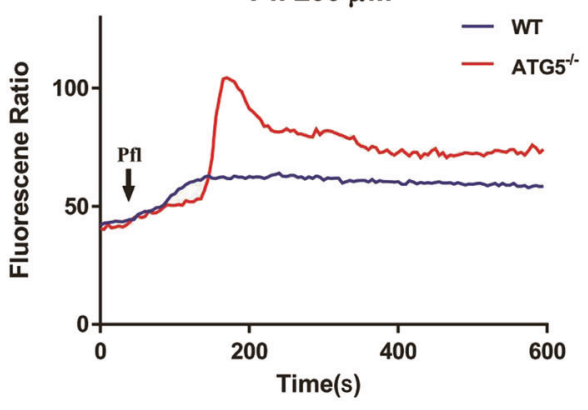

d

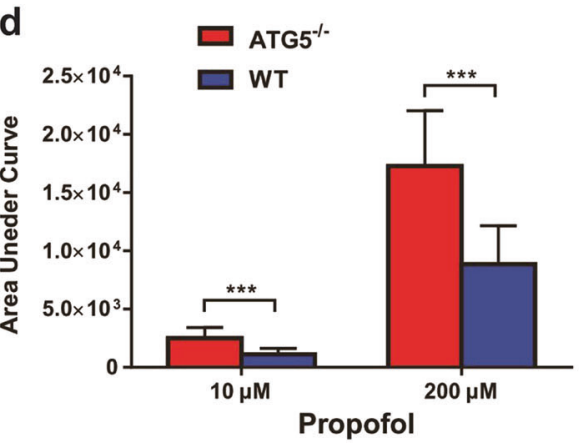

f

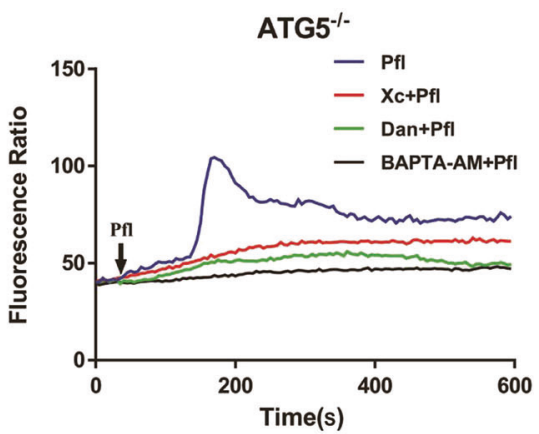

h

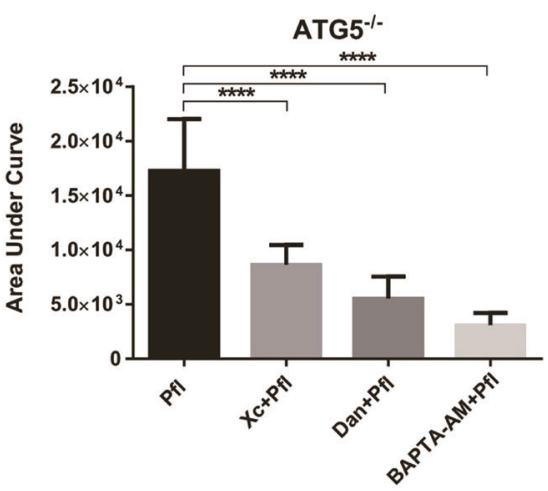

Fig. 5 ATG5 regulates the propofol-induced changes in cytosolic $\mathrm{Ca}^{2+}$ concentration $\left(\left[\mathrm{Ca}^{2+}\right]_{\mathrm{C}}\right)$ by activation of ryanodine $(\mathrm{RYR})$ or InsP $\left(\right.$ Ins $\left.P_{3} \mathrm{R}\right)$ receptors. Average $\mathrm{Ca}^{2+}$ response to $10(\mathbf{a})$ and $200 \mu \mathrm{M}(\mathbf{b})$ propofol $(\mathrm{Pfl})$ in wild-type (WT) and ATG5 ${ }^{-1-} \mathrm{MEFs}$. Changes in the $F_{340} / F_{380}$ ratio from at least 30 single cells in at least three separate experiments were measured to assess the changes of $\left[\mathrm{Ca}^{2+}\right]_{c}$. Ten micrometers vs. $200 \mu \mathrm{M}$ Pfl dose-dependently increased the peak (c) and integrated exposure (d, area under the curve) of [Ca $\left.{ }^{2+}\right]_{c}$ significantly more in ATG5 ${ }^{-/-}$ than in WT MEFs. Average $\left[\mathrm{Ca}^{2+}\right]_{c}$ response to $200 \mu \mathrm{M}$ Pfl in WT (e) or ATG5 ${ }^{-1-}$ (f) MEFs in the presence or absence of antagonists for InsP ${ }_{3} \mathrm{R}$ (xestospongin C, Xc $100 \mathrm{nM}$ ) or RYR (dantrolene, Dan $20 \mu \mathrm{M}$ ) or intracellular $\mathrm{Ca}^{2+}$ chelator (BATPA-AM, $\left.5 \mu \mathrm{M}\right)$. Pfl-mediated $\left[\mathrm{Ca}^{2+}\right]_{c}$ elevation was significantly inhibited by Xc, dantrolene and BAPTA-AM in both WT (g) and ATG5 ${ }^{-1-}$ cells (h), more significantly in the latter. All data are given as the mean \pm SD from at least three separate experiments and analyzed by one-way ANOVA followed by the Tukey's multiple comparison tests. ${ }^{*} P<0.05,{ }^{*} P<0.01,{ }^{* *} P<0.001$, or ${ }^{* * *} P<0.0001$, respectively 

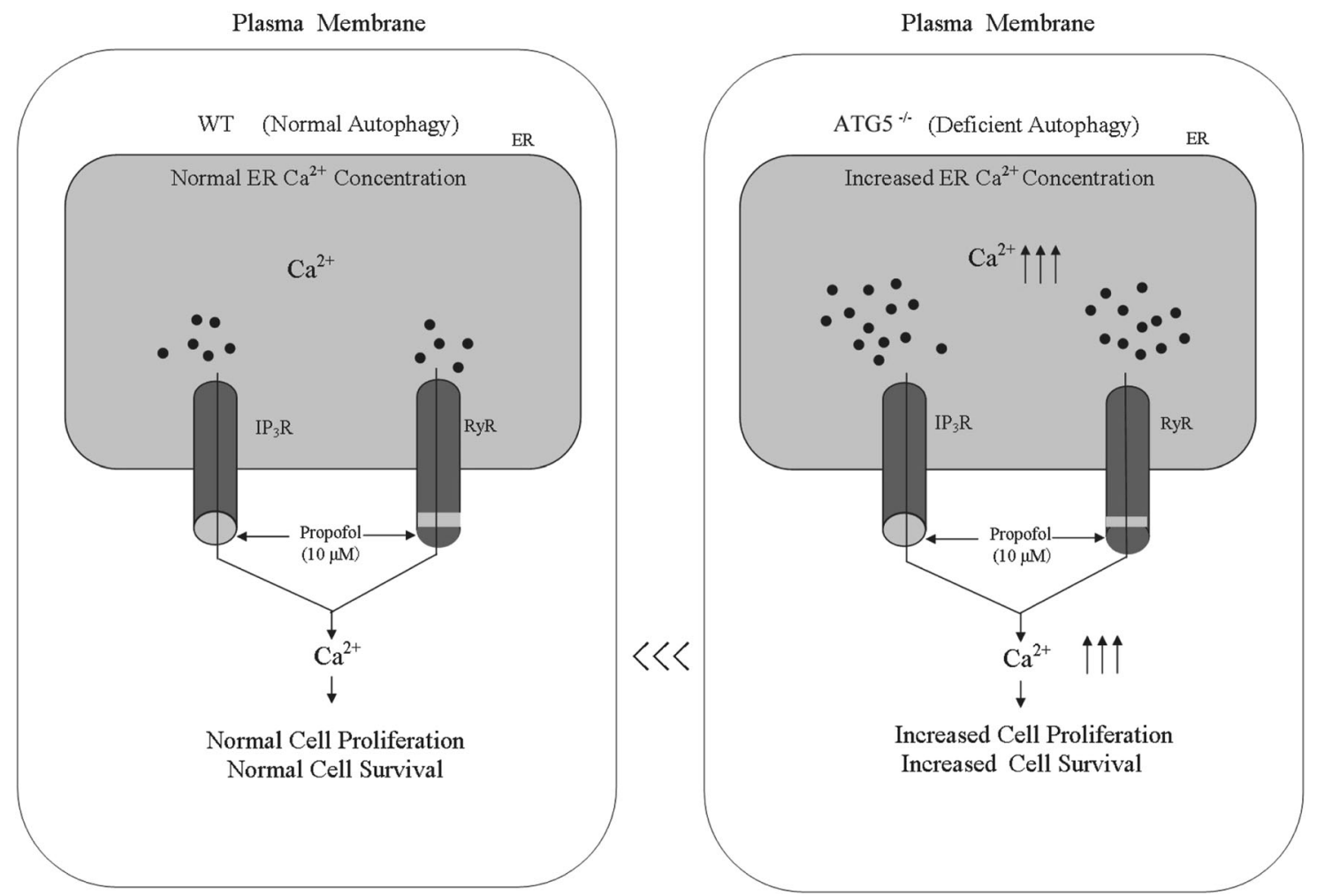

Fig. 6 Propofol at clinically relevant concentrations promotes cell survival and proliferation in autophagy-deficient cells. The ER is expanded, and the basal $\mathrm{Ca}^{2+}$ stores are increased in autophagy-deficient MEF cells. Propofol at clinical concentrations (10 $\left.\mu \mathrm{M}\right)$ significantly induces the release of more $\mathrm{Ca}^{2+}$ from the ER into the cytosol in ATG5 ${ }^{-1-}$ cells than in WT cells via the activation of inositol-1,4,5-trisphosphate receptor $\left(\right.$ Ins $\left.\mathrm{P}_{3} \mathrm{R}\right)$ and/or ryanodine receptor (RyR) calcium channels, favoring cell survival and proliferation

autophagy deficiency has been demonstrated to lead to an imbalance between $\mathrm{Ca}^{2+}$ release/influx or reuptake/extrusion, resulting in higher basal $\left[\mathrm{Ca}^{2+}\right]_{c}$ [34]. In vascular smooth muscle cells (VSMCs) with defective autophagy, cytosolic $\mathrm{Ca}^{2+}$ levels increased under basal conditions, which may be related to decreased plasma membrane $\mathrm{Ca}^{2+}$-ATPase expression in $\mathrm{Atg} 7^{-1-}$ VSMCs, thus hampering $\mathrm{Ca}^{2+}$ extrusion to the extracellular environment [34].

Although anesthetics have been proposed to affect autophagy and cell survival in a dose-dependent manner, with low doses stimulating autophagy and cell survival [35, 36], and high concentrations impairing autophagy flux and causing cell damage $[15,16]$, this may be oversimplified. In the current study, we demonstrated that high doses of propofol induces autophagy in wild type cells, but not in $\mathrm{ATG} 5^{-/-}$cells. We propose an alternative model in which the ER is expanded and $\mathrm{Ca}^{2+}$ stores are increased in autophagy-deficient MEF cells. While this enhances vulnerability to cell death triggered by calcium overload at high propofol doses, propofol at clinically relevant concentrations $(10 \mu \mathrm{M})$ induces a moderate increase in $\mathrm{Ca}^{2+}$ release from the ER into the cytosol, favoring cell survival and proliferation of autophagy-deficient cells (Fig. 6).

In this study, we demonstrated that the effects of propofol on calcium release are modulated by ATG5. Furthermore, propofol at clinically relevant concentrations $(10 \mu \mathrm{M})$ promoted the proliferation of $\mathrm{ATG} 5^{-1-}$ cells through moderately elevated $\left[\mathrm{Ca}^{2+}\right]_{c}$, while at high concentrations $(200 \mu \mathrm{M})$, propofol increased the large outflow of $\mathrm{Ca}^{2+}$ from the ER, inducing the death of $\mathrm{ATG}^{-1-}$ cells. It is not clear whether ATG5 has direct effects on the activation of Ins $\mathrm{P}_{3} \mathrm{R} / \mathrm{RYR}$ or indirect effects via the regulation of autophagy. In addition, it is not clear whether the effect of propofol on intracellular $\mathrm{Ca}^{2+}$ homeostasis is associated with $\mathrm{Ca}^{2+}$ influx from the extracellular space, which requires further study.
Our study has the following limitations: (1). Although these two types of cells provide good tools to investigate the role of ATG5 on the propofol effect on autophagy and its association with cell survival and growth, these cells are fibroblasts and not closely related to neurons. (2). Whether or not ATG5 regulates activation of $\mathrm{InsP}_{3} \mathrm{R} / \mathrm{RYR}$ by either directly interacting with receptor activation or indirectly through changes in lysosome or autophagy function requires further study. (3). This study relied upon the conversion of LC3-I (cytosolic form) to LC3-II (membrane-bound lipidated form) by immunoblotting with and without lysosomal inhibitor treatment, which is a conventional method to monitor cellular autophagic activity [37]. Now with a novel tandem construct (mRFP-GFP-LC3), autophagic flux can also be morphologically traced, although we did not perform this experiment.

In summary, ATG5 plays an essential role in modulating dosedependent propofol effects on autophagy, cell proliferation and cell death related to changes in intracellular $\mathrm{Ca}^{2+}$ homeostasis.

\section{ACKNOWLEDGEMENTS}

We appreciate the valuable discussion from Maryellen Eckenhoff, Roderic Eckenhoff and editing assistance from Divakara Gouda at the Department of Anesthesiology, University of Pennsylvania, Philadelphia, USA. Supported by grants to HW from the NIH (R01GM084979, 3R01GM084979-02S1, and 2R01GM084979-06A1) and R01AG026389-10S1 to CTC. Supported by grants to ZX from Shanghai Municipal Health Bureau (201840149). Supported by grants to ZX from the National Natural Science Foundation of China (81971418). Supported by grants to YW from the National Natural Science Foundation of China (81503663).

\section{AUTHOR CONTRIBUTIONS}

HFW designed research; ZDX, YW, and GL performed research; ZDX, HFW, and CTC analyze and interpret data; ZDX, HFW, CTC, ZQL, and WHM wrote the paper. 


\section{ADDITIONAL INFORMATION}

Competing interests: Hua-feng Wei is a member of Advisory Board on March 10, 2017 at Eagle Pharmaceutical Company, New Jersey, USA, which produce and sale Ryanodex, a new formula of dantrolene. The dantrolene used in this study was purchased from a different company. No other authors state conflict of interest.

\section{REFERENCES}

1. Kuma A, Hatano M, Matsui M, Yamamoto A, Nakaya H, Yoshimori T, et al. The role of autophagy during the early neonatal starvation period. Nature. 2004;432:1032-6.

2. O'Sullivan TE, Geary CD, Weizman OE, Geiger TL, Rapp M, Dorn GW 2nd, et al. Atg5 is essential for the development and survival of innate lymphocytes. Cell Rep. 2016;15:1910-9.

3. Lopez-Soto A, Bravo-San Pedro JM, Kroemer G, Galluzzi L, Gonzalez S. Involvement of autophagy in NK cell development and function. Autophagy. 2017;13:633-6.

4. Shi M, Zhang T, Sun L, Luo Y, Liu DH, Xie ST, et al. Calpain, Atg5 and Bak play important roles in the crosstalk between apoptosis and autophagy induced by influx of extracellular calcium. Apoptosis. 2013;18:435-51.

5. Kania E, Pajak B, Orzechowski A. Calcium homeostasis and ER stress in control of autophagy in cancer cells. Biomed Res Int. 2015;2015:352794.

6. Medina DL, Di Paola S, Peluso I, Armani A, De Stefani D, Venditti R, et al. Lysosomal calcium signalling regulates autophagy through calcineurin and TFEB. Nat Cell Biol. 2015;17:288-99.

7. Lv X, Jiang H, Li B, Liang Q, Wang S, Zhao Q, et al. The crucial role of Atg5 in cortical neurogenesis during early brain development. Sci Rep. 2014;4:6010.

8. Pua HH, Dzhagalov I, Chuck M, Mizushima N, He YW. A critical role for the autophagy gene Atg5 in T cell survival and proliferation. J Exp Med. 2007;204:25-31.

9. Watson AS, Riffelmacher T, Stranks A, Williams O, De Boer J, Cain K, et al. Autophagy limits proliferation and glycolytic metabolism in acute myeloid leukemia. Cell Death Discov. 2015;1. pii: 15008

10. Chen D, Zhu C, Wang X, Feng X, Pang S, Huang W, et al. A novel and functional variant within the ATG5 gene promoter in sporadic Parkinson's disease. Neurosci Lett. 2013;538:49-53.

11. Liu Q, Chen L, Atkinson JM, Claxton DF, Wang HG. Atg5-dependent autophagy contributes to the development of acute myeloid leukemia in an MLL-AF9-driven mouse model. Cell Death Dis. 2016;7:e2361.

12. Liu $\mathrm{H}$, He Z, Simon HU. Protective role of autophagy and autophagy-related protein 5 in early tumorigenesis. J Mol Med. 2015;93:159-64.

13. Ge J, Chen Z, Huang J, Chen J, Yuan W, Deng Z, et al. Upregulation of autophagyrelated gene-5 (ATG-5) is associated with chemoresistance in human gastric cancer. PLoS ONE. 2014;9:e110293.

14. Nishida Y, Arakawa S, Fujitani K, Yamaguchi H, Mizuta T, Kanaseki T, et al. Discovery of Atg5/Atg7-independent alternative macroautophagy. Nature. 2009;461:654-8.

15. Qiao H, Li Y, Xu Z, Li W, Fu Z, Wang Y, et al. Propofol affects neurodegeneration and neurogenesis by regulation of autophagy via effects on intracellular calcium homeostasis. Anesthesiology. 2017;127:490-501.

16. Ren G, Zhou Y, Liang G, Yang B, Yang M, King A, et al. General anesthetics regulate autophagy via modulating the inositol 1,4,5-trisphosphate receptor: implications for dual effects of cytoprotection and cytotoxicity. Sci Rep. 2017;7:12378.

17. Xia HG, Zhang L, Chen G, Zhang T, Liu J, Jin M, et al. Control of basal autophagy by calpain 1 mediated cleavage of ATG5. Autophagy. 2010;6:61-6.

18. Jia W, He MX, McLeod IX, He YW. Autophagy, a novel pathway to regulate calcium mobilization in T lymphocytes. Front Immunol. 2013;4:179.
19. Liu F, Rainosek SW, Sadovova N, Fogle CM, Patterson TA, Hanig JP, et al. Protective effect of acetyl-L-carnitine on propofol-induced toxicity in embryonic neural stem cells. Neurotoxicology. 2014;42:49-57.

20. Twaroski DM, Yan Y, Olson JM, Bosnjak ZJ, Bai X. Down-regulation of microRNA21 is involved in the propofol-induced neurotoxicity observed in human stem cell-derived neurons. Anesthesiology. 2014;121:786-800.

21. Wang JW, Cheng WW, Xu T, Yang ZY. Propofol induces apoptosis and inhibits the proliferation of rat embryonic neural stem cells via gamma-aminobutyric acid type A receptor. Genet Mol Res. 2015;14:14920-8.

22. Liu C, DeRoo EP, Stecyk C, Wolsey M, Szuchnicki M, Hagos EG. Impaired autophagy in mouse embryonic fibroblasts null for Kruppel-like Factor 4 promotes DNA damage and increases apoptosis upon serum starvation. Mol Cancer. 2015;14:101.

23. Hollomon MG, Gordon N, Santiago-O'Farrill JM, Kleinerman ES. Knockdown of autophagy-related protein 5, ATG5, decreases oxidative stress and has an opposing effect on camptothecin-induced cytotoxicity in osteosarcoma cells. BMC Cancer. 2013;13:500.

24. Yang $H$, Liang $G$, Hawkins BJ, Madesh $M$, Pierwola A, Wei $H$. Inhalational anesthetics induce cell damage by disruption of intracellular calcium homeostasis with different potencies. Anesthesiology. 2008;109:243-50.

25. Wang $Q$, Liang G, Yang $H$, Wang S, Eckenhoff MF, Wei H. The common inhaled anesthetic isoflurane increases aggregation of huntingtin and alters calcium homeostasis in a cell model of Huntington's disease. Toxicol Appl Pharmacol. 2011;250:291-8.

26. Joseph JD, Peng Y, Mak DO, Cheung KH, Vais H, Foskett JK, et al. General anesthetic isoflurane modulates inositol 1,4,5-trisphosphate receptor calcium channel opening. Anesthesiology. 2014;121:528-37.

27. Xie Z, Dong Y, Maeda U, Alfille P, Culley DJ, Crosby G, et al. The common inhalation anesthetic isoflurane induces apoptosis and increases amyloid beta protein levels. Anesthesiology. 2006;104:988-94.

28. Komita $M$, Jin $H$, Aoe $T$. The effect of endoplasmic reticulum stress on neurotoxicity caused by inhaled anesthetics. Anesth Analg. 2013;117:1197-204.

29. Palanisamy A, Friese MB, Cotran E, Moller L, Boyd JD, Crosby G, et al. Prolonged treatment with propofol transiently impairs proliferation but not survival of rat neural progenitor cells in vitro. PLoS One. 2016;11:e0158058.

30. Choi YJ, Jeon SK, Kim J, Park Y, Yoon SZ, Sun K. The effects of intravenous anesthetics on mouse embryonic fibroblast viability and proliferation. J Anesth. 2012;26:675-81.

31. Li Q, Liu Y, Sun M. Autophagy and Alzheimer's disease. Cell Mol Neurobiol. 2017;37:377-88.

32. Whyte LS, Lau AA, Hemsley KM, Hopwood JJ, Sargeant TJ. Endo-lysosomal and autophagic dysfunction: a driving factor in Alzheimer's disease? J Neurochem. 2017;140:703-17.

33. Jia W, Pua HH, Li QJ, He YW. Autophagy regulates endoplasmic reticulum homeostasis and calcium mobilization in T lymphocytes. J Immunol. 2011;186:1564-74.

34. Michiels CF, Fransen P, De Munck DG, De Meyer GR, Martinet W. Defective autophagy in vascular smooth muscle cells alters contractility and $\mathrm{Ca}^{2+}$ homeostasis in mice. Am J Physiol Heart Circ Physiol. 2015;308:H557-67.

35. Chang CY, Chen PH, Lu SC, Hsieh MC, Lin CW, Lee HM, et al. Propofol-enhanced autophagy increases motility and angiogenic capacity of cultured human umbilical vascular endothelial cells. Life Sci. 2015;142:49-59.

36. $\mathrm{Ha} \mathrm{JH}$, Noh HS, Shin IW, Hahm JR, Kim DR. Mitigation of $\mathrm{H}_{2} \mathrm{O}_{2}$-induced autophagic cell death by propofol in H9c2 cardiomyocytes. Cell Biol Toxicol. 2012;28:19-29.

37. Mizushima N, Yoshimori T, Levine B. Methods in mammalian autophagy research. Cell. 2010;140:313-26. 